\title{
MULHERES EM MARCHA: CARTOGRAFIA FOTOGRÁFICA E AFETIVA DE MOVIMENTOS DE MULHERES
}

\section{WOMEN IN ACTION: A PHOTO-AFFECTIVE CARTOGRAPHY OF WOMEN MOVEMENTS}

\section{Cecília Moreyra de Figueiredo}

cissafig@gmail.com

Doutora em psicossociologia de comunidades, professora do curso de jornalismo da Universidade Federal Rural do Rio de Janeiro e Fotógrafa.

ORCID: https://orcid.org/0000-0001-7444-4825

Este Ensaio é fruto de uma cartografia fotográfica e afetiva de movimentos recentes, protagonizados por mulheres no Brasil. As imagens se produzem no fluxo da vivência das situações retratadas e através de um olhar comprometido com a particularidade de cada situação, revelando em suas narrativas, seu sentido ético, estético, político e poético. A produção fotográfica está orientada pelo sentido que Debord (1967) define como deriva, uma técnica de passagem por ambiências variadas na qual o sujeito se deixa conduzir pelas solicitações do território e dos encontros (DEBORD, 1967). A fotografia é uma linguagem potente para fazer pensar sobre realidades sociais diversas em um diálogo entre a deriva de Debord e o que o fotógrafo chileno Sergio Larrain chamou de estado de graça, no qual a pessoa que fotografa se deixa permear pela imagem e, sem buscar a fotografia, se abre para que ela surja enquanto narrativa.

No entanto, a deriva e o estado de graça não são frutos de acasos fortuitos, mas sim o resultado da observação e da interpretação das realidades permeadas pela sensibilidade. Fotografar e cartografar significam, em minha trajetória de pesquisadora na psicossociologia, o deslocar-se entre territórios ou situações sociais, formando representações e afetos, capturando encontros e modos de simbolizá-los em sua especificidade e inteligibilidade, segundo códigos intersubjetivamente partilhados e interculturalmente definidos (INGOLD, 2005), permanecendo atento às variações da subjetividade e da paisagem (PASSOS et al., 2015). Se para Ingold (2005), conhecemos enquanto caminhamos, e não antes de caminhar, só é possível fotografar no presente e na interação com a realidade vivenciada.

Cartografar pressupõe a delimitação de um campo problemático, sendo necessário reconhecer que, no final, a obra tende a estar aberta, com uma tarefa inconclusa e convidativa para novas pesquisas (PASSOS et al., 2015). A questão inicial desta cartografia é quais sentidos e sentimentos são motores destes movimentos de mulheres e quais marcas estéticas podem emergir nestas narrativas. $\mathrm{O}$ trabalho na pesquisa consistiu em produzir e curar imagens que formam um cartograma, o 
resultado de um exercício de mapeamento visual, que significa o deslocamento entre territórios ou situações sociais, formando representações de ordem afetiva. No processo cartográfico, o permanente se torna transitório e apreende marcas historicamente constituídas, mas deixa lastros que dão origem a múltiplas apropriações, e a fotografia nos permite ver e pensar o que não parece razoável, criando realidades que ultrapassem o sentido de adequação. Um dispositivo de produção de sentidos e de categorias sociais que contêm ao mesmo tempo elementos de poder e de contrapoder (FIGUEIREDO, 2017).

Reúno nesse ensaio fotográfico 14 imagens que representam diferentes movimentos políticos de mulheres, as quais acompanhei durante os anos de 2018 e 2019, realizados em Belo Horizonte, Rio de Janeiro e Brasília como parte de coletivo FotoMinas de mulheres fotógrafas da Universidade Federal Rural do Rio de Janeiro, e como parte da Coletiva de Comunicação da Articulação Nacional de Agroecologia.

As fotos são o lugar principal de produção de reflexão ancoradas em uma iconosfera (MENESES, 2014), um ambiente visual ou conjunto de imagens que guia a leitura sobre determinado grupo ou determinada situação social. Captar a iconosfera é identificar os sistemas de comunicação visual, que são referências, que transmitem informação e que também podem ser chamadas de imagens identitárias (FIGUEIREDO, 2017). As imagens escapam ao sentido de um instantâneo aleatório para remontar recortes da realidade e produzir uma nova narrativa que desvele as representações das identidades psicossociais (HARTMAN, 2004). Guardo para as legendas das fotos algumas reflexões sobre as representações e sentidos que emergem nos discursos, buscando dialogar com a minha vivência cartográfica dos eventos e das realidades.

A fotografia é o processo de coleta de dados ao mesmo tempo em que enuncia as reflexões realizadas, ela é o método e a ferramenta, o lugar de produção de narrativa e a própria narrativa. O fazer fotográfico constitui um vínculo de relações, compartilha sentidos e acaba por se tornar um poderoso instrumento de desconstrução dos modos tradicionais de fazer pesquisa (NOVAES, 1996). O potencial da imagem em produzir intervivências e intercomunicação durante a pesquisa (BRANDÃO, 2005) converge para uma câmera interativa onde a imagem captada é o resultado de escolhas de enquadramentos, seleção de elementos, fruto de trocas entre quem fotografa e quem é fotografado (FIGUEIREDO, 2017). Este movimento de diálogo também é chamado de compartilhamento do ato fotográfico (MARTINS, 2013) e nele estão presente uma série de escolhas que compõem um quadro recheado de recursos simbólicos e elementos que ampliam as possibilidades de expressão das identidades dos sujeitos. A abordagem de uma fotografia reflexiva produz imagens repletas de sentidos, imagens que falam e são pensativas, pois fazem refletir (BARTHES, 1979). 
Neste espaço de negociação de sentidos, em que forças disputam narrativas e imaginários se cruzam e se afrontam, a imagem final é uma só. Esta realidade única transborda interpretações para outras esferas de produção de discurso, trazendo para a negociação simbólica aqueles que observam e se deixam permear pela imagem e sua narrativa.

\section{REFERÊNCIAS}

BARTHES, Roland. A Câmara Clara. Lisboa: Edições 70, 1979.

BRANDÃO, Carlos. R. Escrito com o Olho. In: MARTINS, C. ECKERT, S. C. NOVAES (Orgs.). O imaginário e o poético nas ciências sociais. Bauru, SP, Edusc, 2005.

DEBORD, Guy. A Sociedade do Espetáculo. Paris: Buchet Chastel, 1967. FIGUEIREDO, Cecília. Imagens do Invisível: Sentidos e Sentimentos do Rural-Urbano-Rural do Rio de Janeiro através de retratos fotográficos compartilhados. 2017. 143 f. Tese (Doutorado em Psicossociologia de Comunidades e Ecologia Social) - EICOS, UFRJ, 2017.

HARTMANN, L. Aqui nessa fronteira onde tú vê beira de linha tu vai ver cuento: tradições orais na fronteira entre Argentina, Brasil e Uruguai. 2004. 360 f. Tese (Doutorado em Antropologia Social) - Universidade Federal de Santa Catarina, 2004.

INGOLD, Timothy. Jornada ao longo de um caminho de vida - mapas, descoberta-de-caminho e navegação. Religião e Sociedade, Rio de Janeiro, v. 25, n. 1, 2005.

MARTINS, José. S. Sociologia da fotografia e da imagem. São Paulo: Contexto, 2013.

MENESES, Ulpiano. T. Rumo a uma "História visual". In: MARTINS, C.; ECKERT, S. C.; NOVAES, Sylvia. C. O Silêncio Eloquente das imagens fotográficas e sua importância na etnografia. Cadernos de Arte e Antropologia, v. 3, n. 2, p. 57-67, 2014.

NOVAES, S.C. Um casamento no Paquistão: na captura de imagens. $\mathrm{Ca}$ dernos de Antropologia e Imagem, v. 3, 1996.

PASSOS, Eduardo; KASTRUP, V.; ESCÓSSIA, L. Pistas do método da Cartografia: Pesquisa-intervenção e produção de subjetividade. Porto Alegre: Sulina, 2015. 


\section{MULHERES EM MARCHA 1}

O deslocamento no espaço fica mais difícil a cada momento. Percebo que já não posso mais escolher o ângulo das fotos, não posso me mover e antes que não possa mais levantar os braços ergo a câmera com o visor voltado para baixo. Não escuto nada, atenta ao balé de imagens que me inunda de sentidos. Todas levantam seus braços, seus estandartes, suas bandeiras, suas lentes, suas vozes e os sinalizadores de fumaça lilás pintam a imagem no visor da câmera.

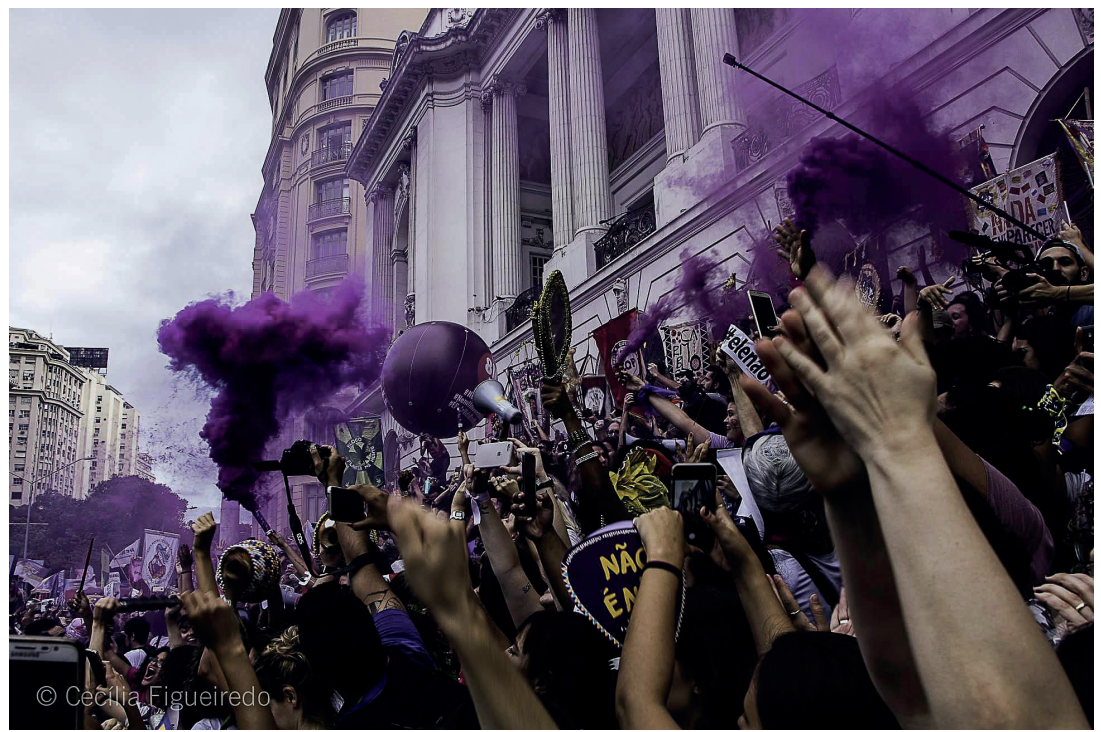

Mulheres pela democracia, Rio de Janeiro, 2018.

\section{MULHERES EM MARCHA 2}

Mulheres se movimentam pela divisão justa do trabalho doméstico e por igualdade salarial. Mulheres se movimentam por mais espaço no campo político e por mais participação nos processos decisórios. Nem sempre a marcha é deslocamento no espaço. Marchar é deslocar as estruturas sociais que podem ser estampadas nas roupas e seguir em uma marcha própria por outros espaços de diálogo.

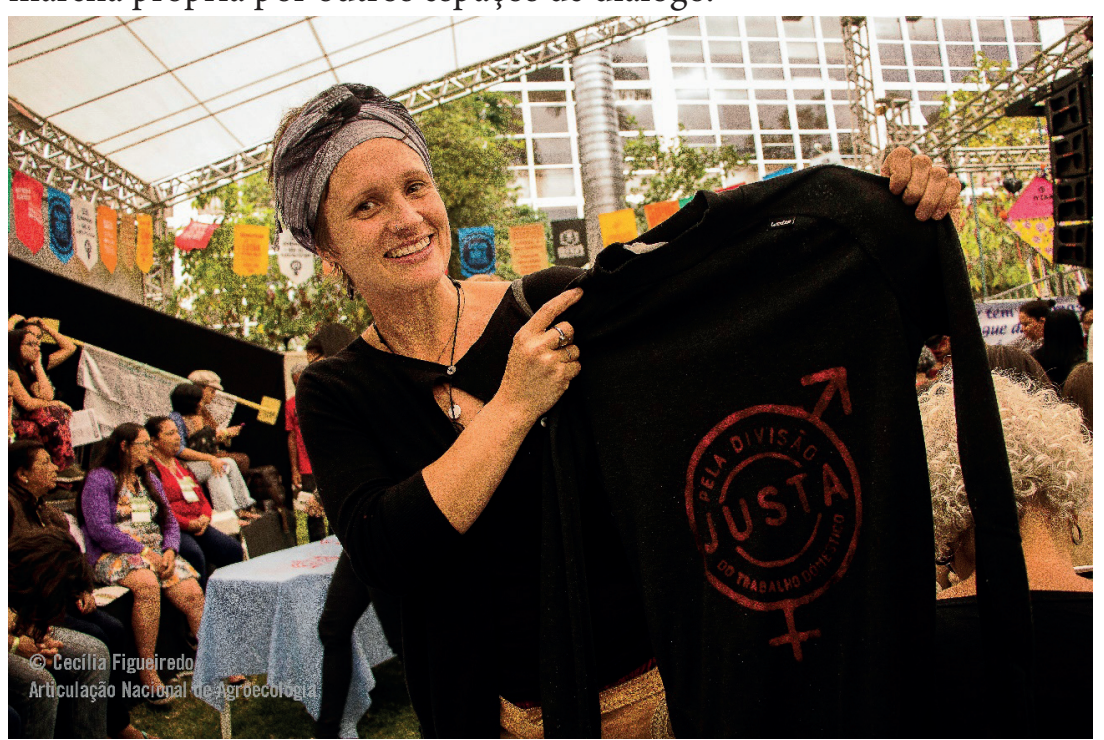

Plenária das mulheres do IV Encontro Nacional de Agroecologia, Belo Horizonte, 2019. 


\section{MULHERES EM MARCHA 3}

Mulheres se movimentam pelo respeito aos seus corpos e pela saúde reprodutiva, apontando para a gritante desigualdade racial presente desde o nascimento.

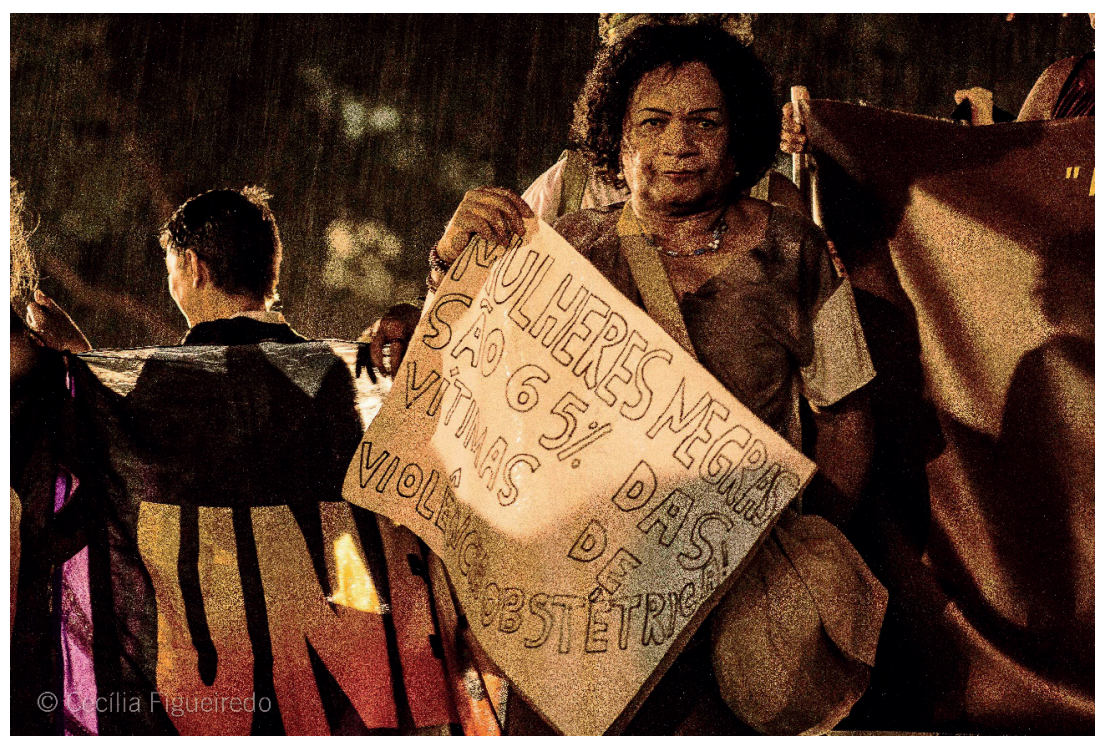

8M, Rio de Janeiro, 2018.

\section{MULHERES EM MARCHA 4}

Quando o diálogo se dá através da imagem o ato fotográfico é compartilhado. Eu aponto a câmera, e ela se vê na lente. O punho erguido é o sinal para o click.

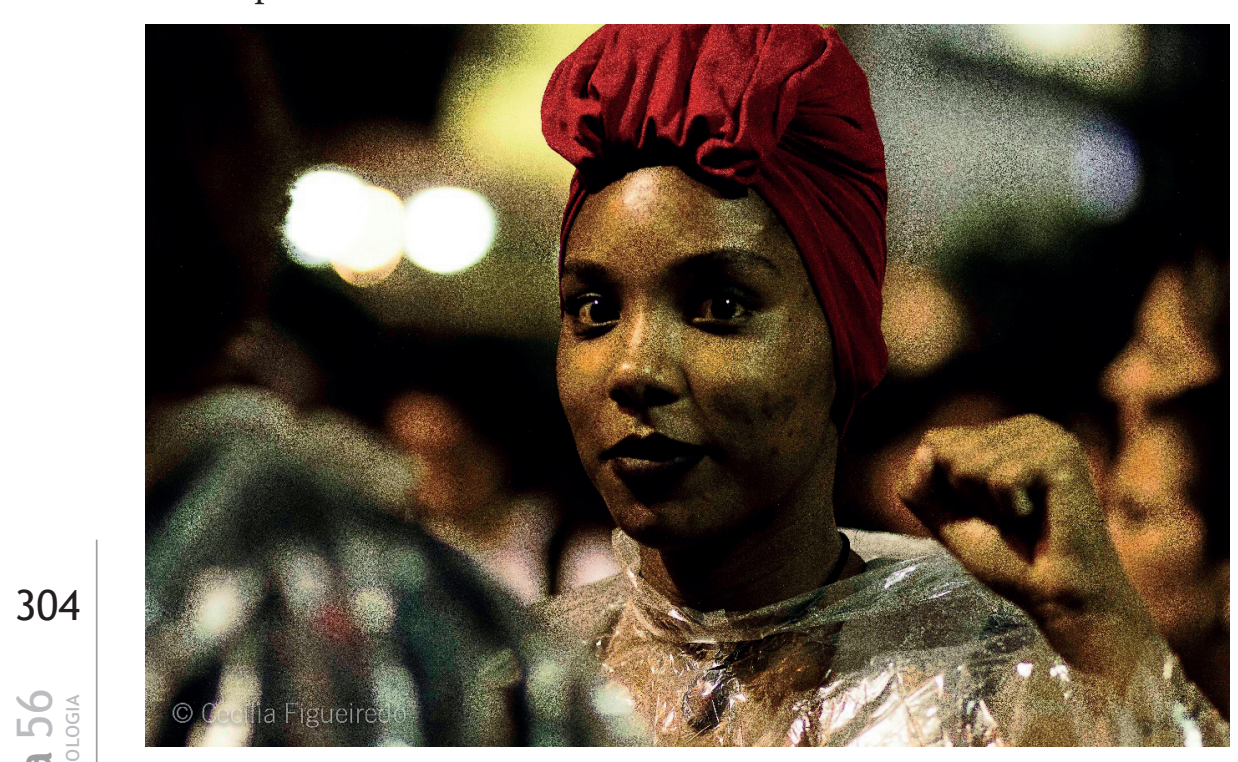

8M, Rio de Janeiro, 2018. 


\section{MULHERES EM MARCHA 5}

Mulheres se movimentam por mais encontros, por mais espaços de troca sincera e solidária. Mulheres se movimentam por outras mulheres.

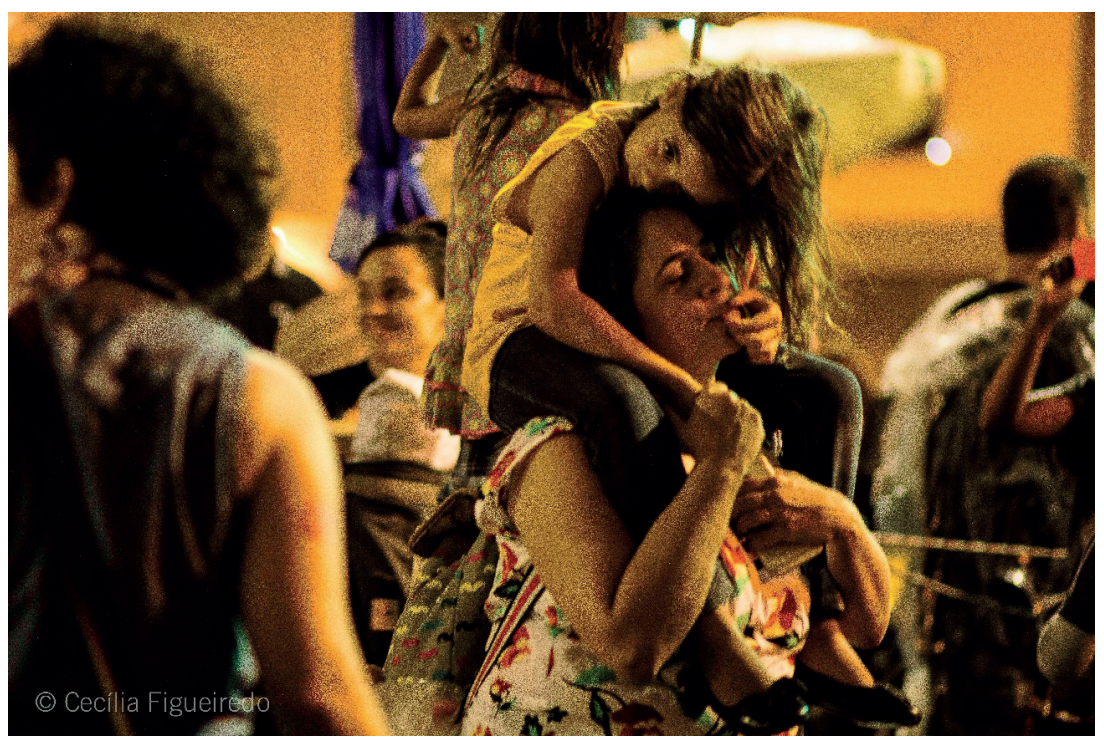

8M, Rio de Janeiro, 2018.

\section{MULHERES EM MARCHA 6}

Mulheres marcham pela desconstrução dos valores tradicionais e das formas tradicionais de fazer política. Irreverência com consequên-

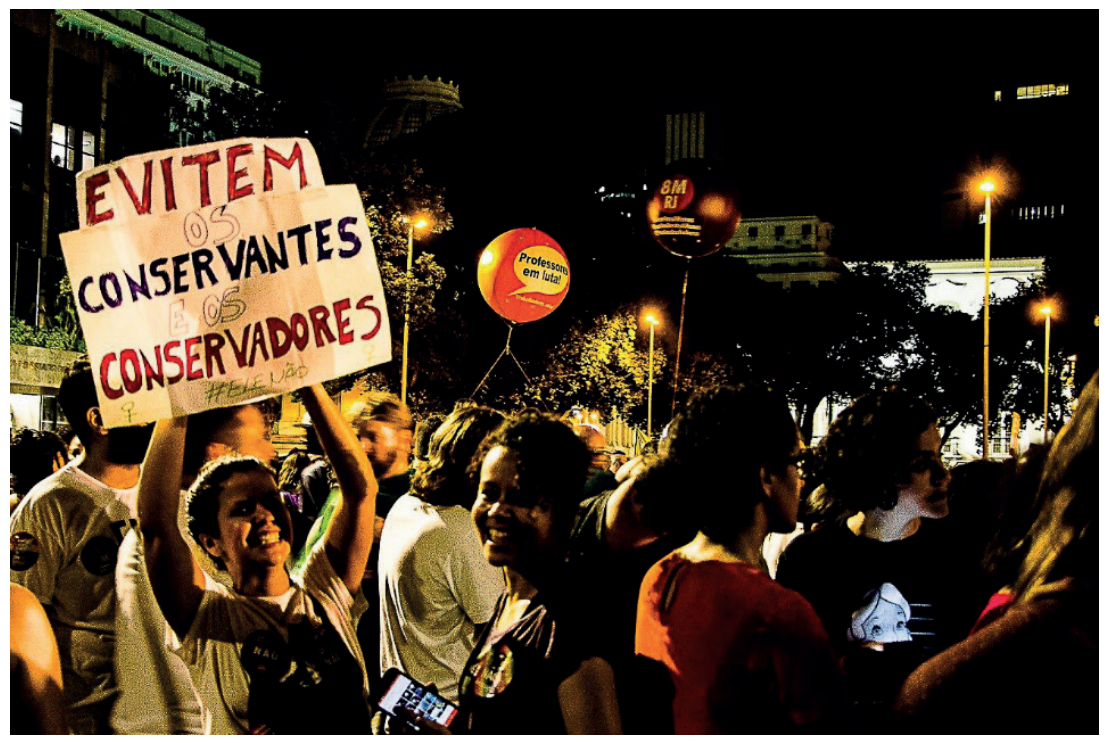

Mulheres pela democracia, Rio de Janeiro, 2018. 


\section{MULHERES EM MARCHA 7}

Mulheres se movimentam por igualdade de direitos, reconhecimento e visibilidade. No fluxo da dança, as mulheres da etnia Xavante trazem suas cores, suas contas, seus símbolos, seu ritmo, sua identidade e sua organização.

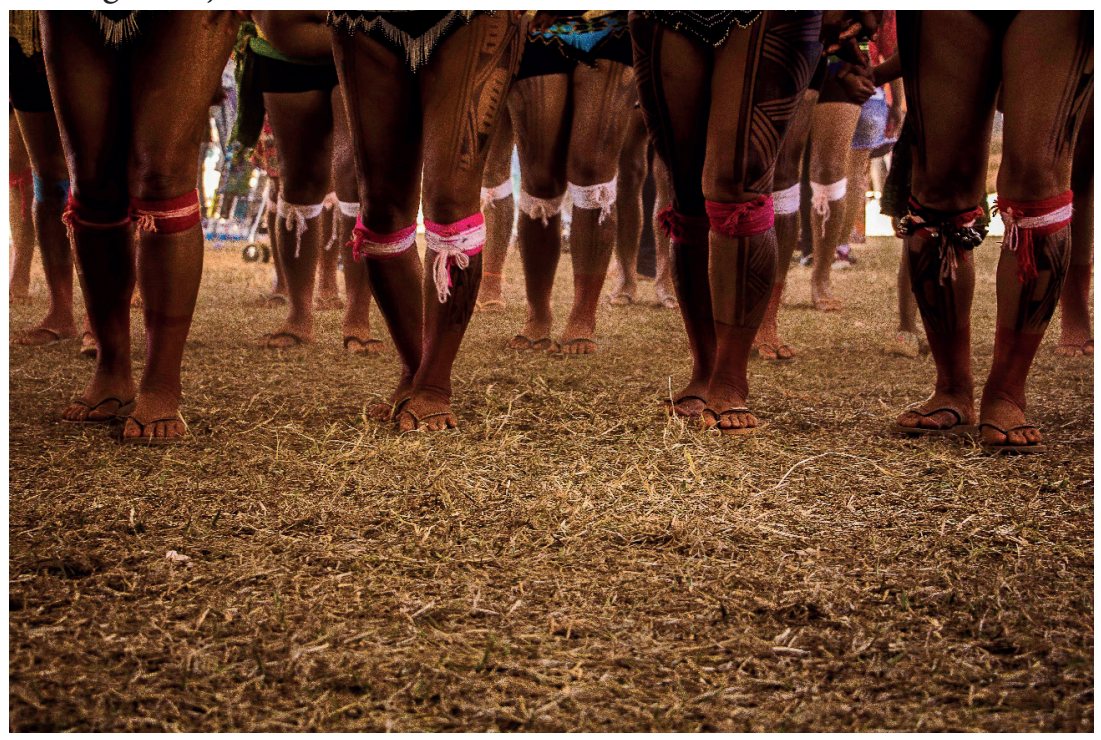

Marcha das mulheres indígenas, Brasília, 2019.

\section{MULHERES EM MARCHA 8}

Mulheres de movimentam pelos encontros geracionais, pela ancestralidade, liberdade religiosa, valorização de seus conhecimentos.

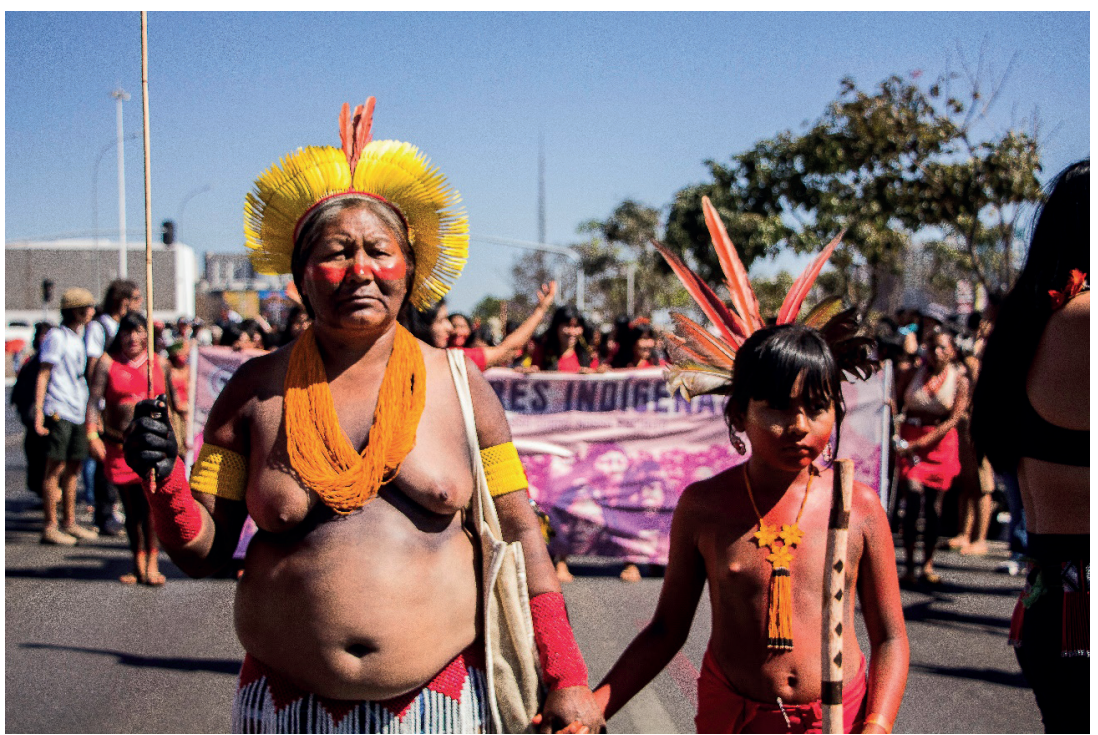

Marcha das Mulheres Indígenas, Brasília, 2019. 


\section{MULHERES EM MARCHA 9}

Mulheres marcham pela ampliação do espaço de participação política. Aqui o dentro e o fora se sobrepõem nas figuras da mulher indígena que dança e a estrutura formal do espaço político.

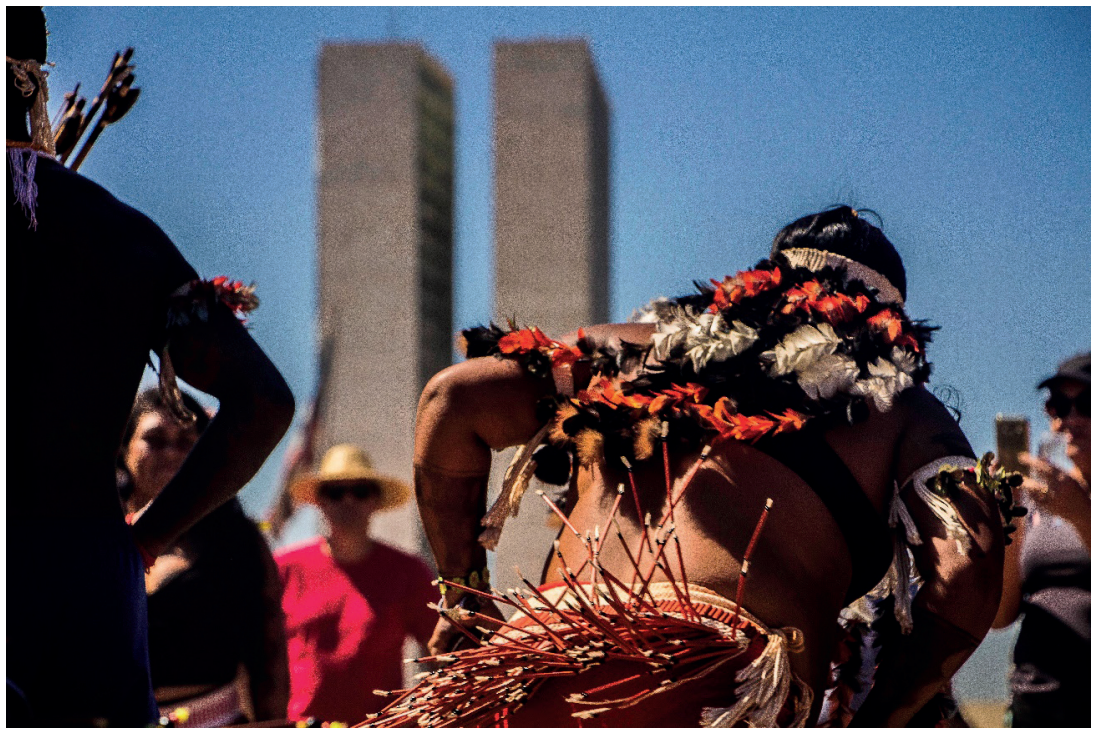

Marcha das mulheres indígenas, Brasília, 2019.

\section{MULHERES EM MARCHA 10}

Mulheres se movimentam pela terra, pelas águas e pelas florestas.

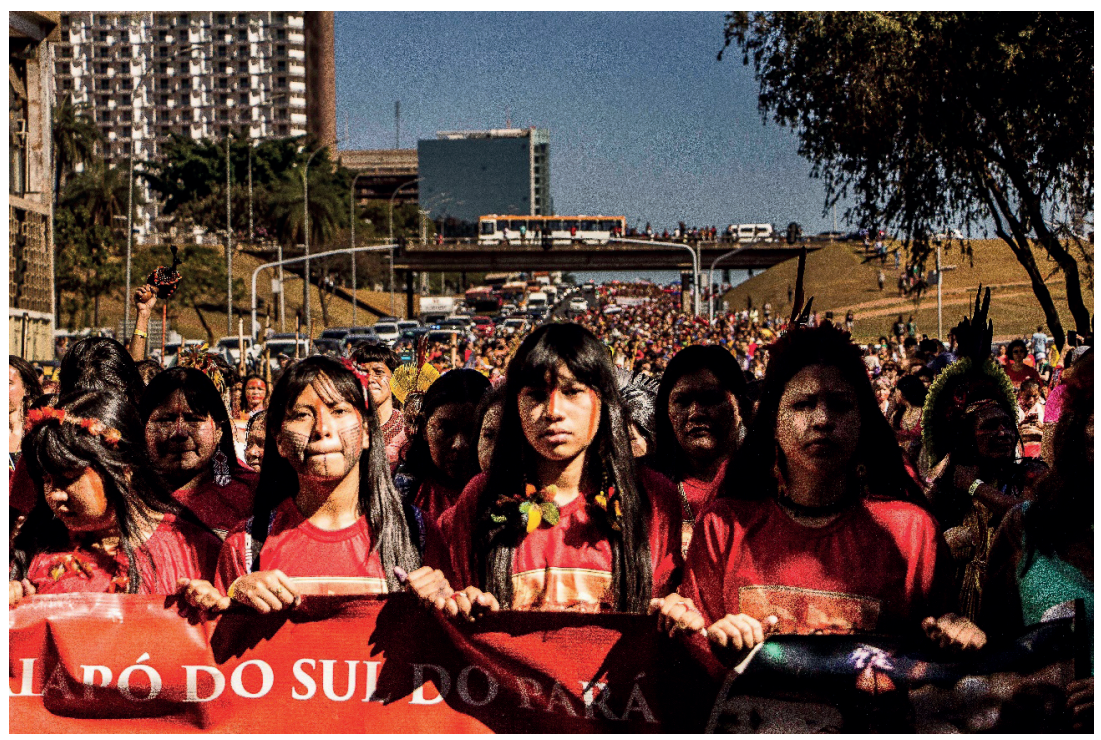

Marcha das mulheres indígenas, Brasília, 2019. 


\section{MULHERES EM MARCHA 11}

Mulheres diversas, mas não dispersas, trazem as flores estampadas em si e lideram a marcha que encerra o IV Encontro Nacional de Agroecologia convocando para a Marcha das Margaridas do ano seguinte.

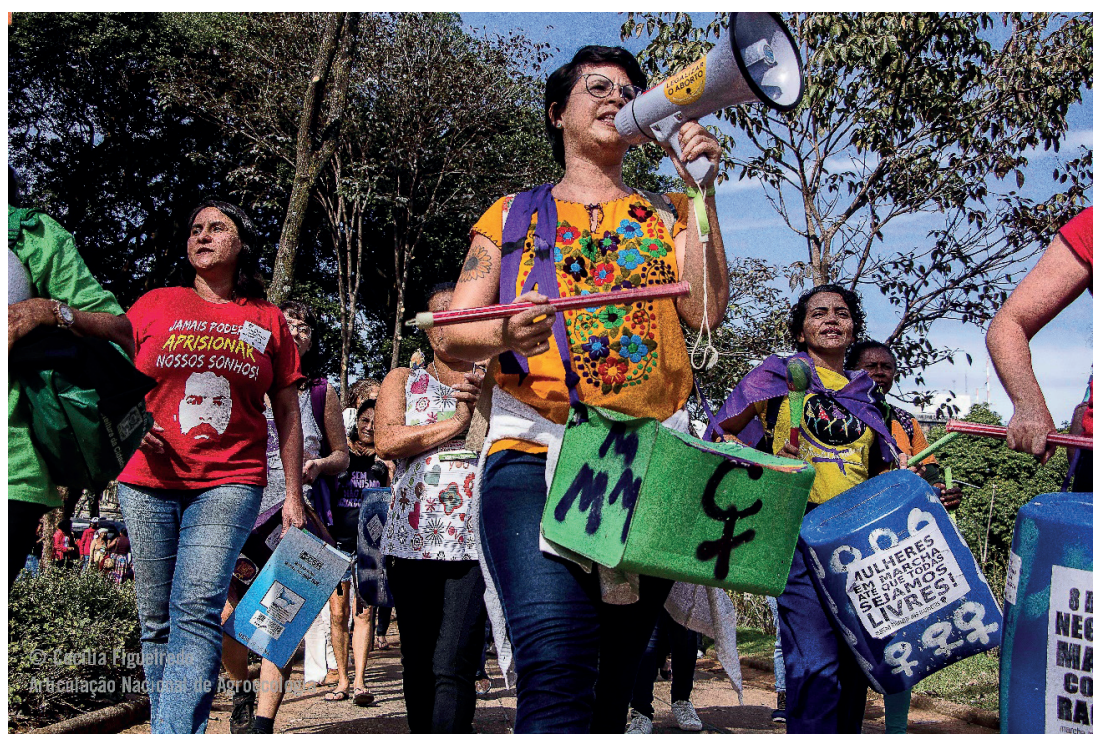

Belo Horizonte, 2018.

\section{MULHERES EM MARCHA 12}

Margarida Alves não é mais só uma mulher agricultora, ela é um símbolo que mobiliza 100 mil outras margaridas para marchar desde suas casas, seus sítios, suas comunidades. De todos os estados do Brasil, elas se encontram para tomar as ruas da capital do pais e propagar mensagens de luta, solidariedade e participação.

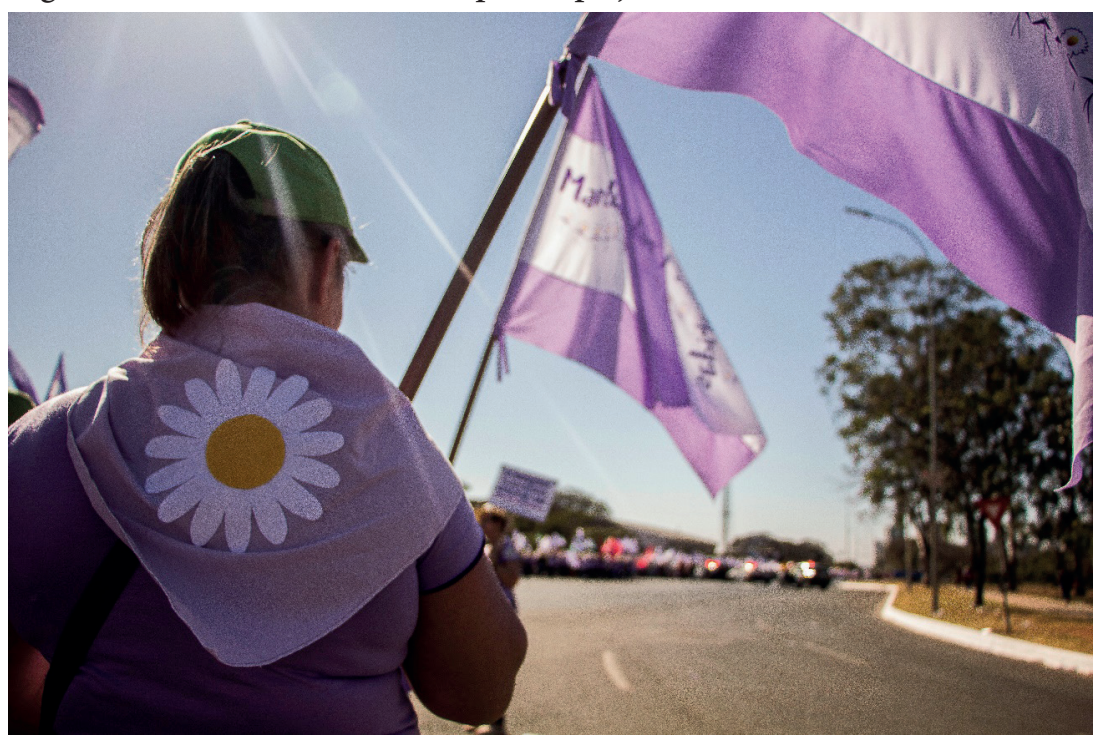

Marcha das margaridas, Brasília, 2019. 


\section{MULHERES EM MARCHA 13}

Margaridas seguem em marcha até que todas sejam livres.

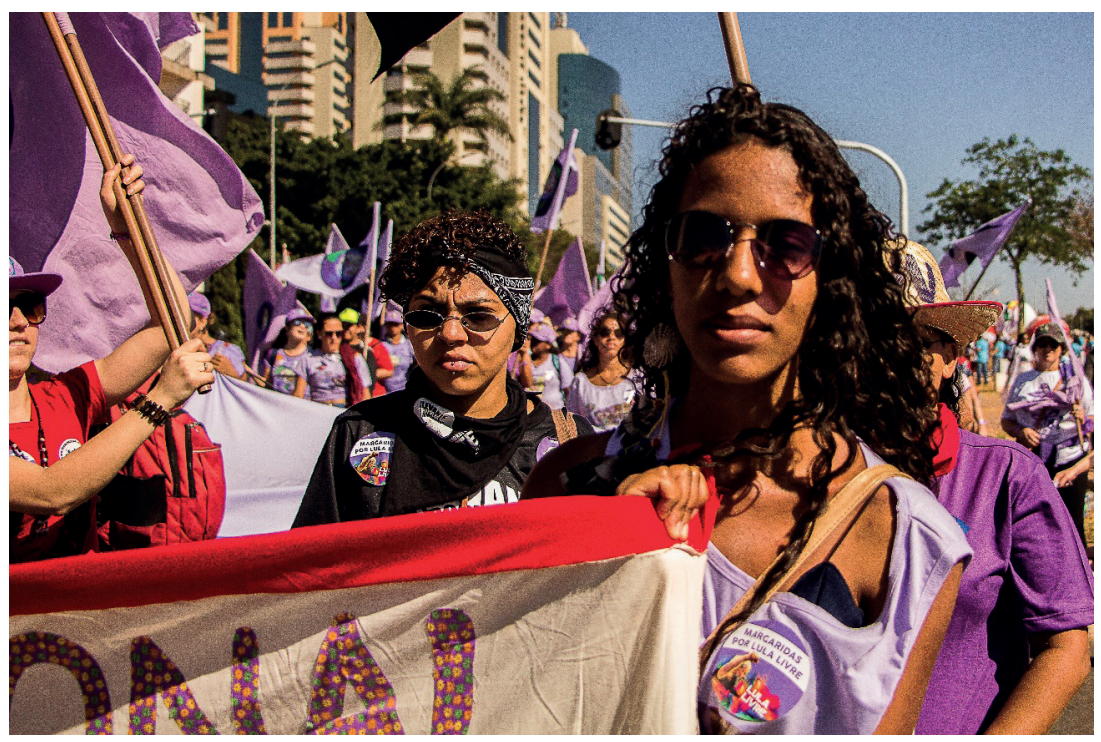

Marcha das margaridas, Brasília, 2019.

\section{MULHERES EM MARCHA 14}

Mulheres se movimentam e carregam bandeiras pelo fim da violência de gênero e pelo respeito às diversidades. Margaridas são muitas.

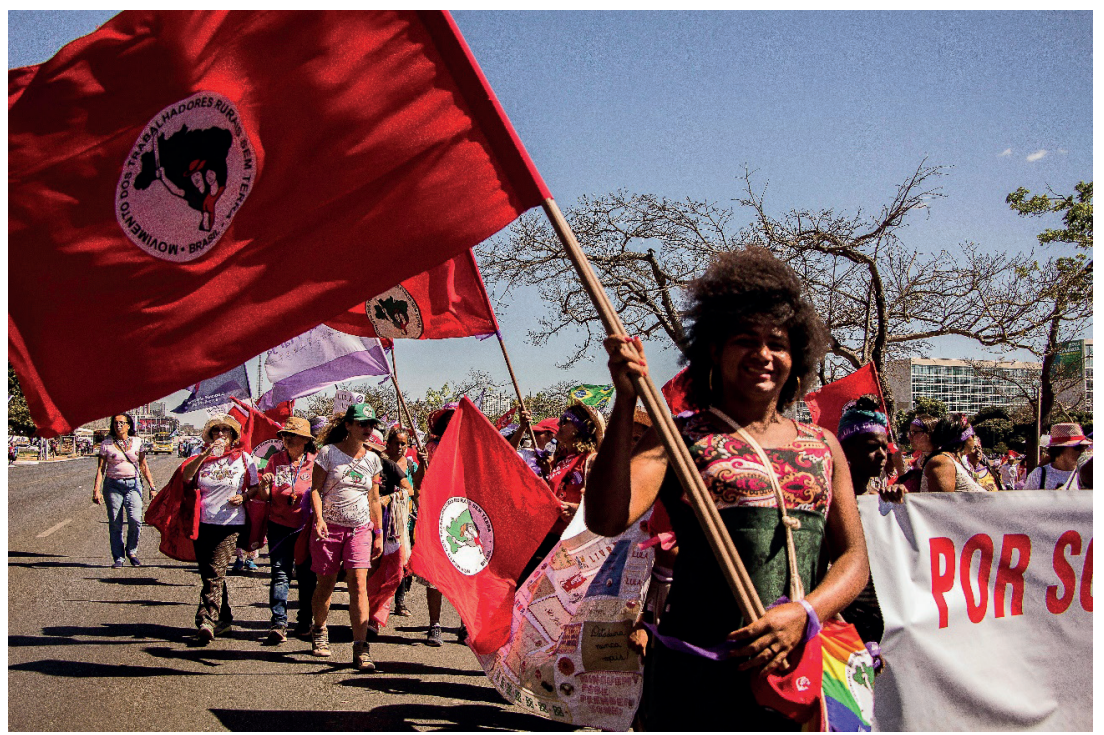

Marcha das margaridas, Brasília, 2019. 